\title{
Insomnia Fighting with Red Led Pulsations
}

\author{
Pierre-Alain Grounauer ${ }^{1}$, Bastien Métraux ${ }^{2}$ \\ ${ }^{1}$ University Eye Clinic, Lausanne, Switzerland \\ ${ }^{2}$ Morges Hospital, Switzerland \\ Email: grounauer@visiocard.ch
}

How to cite this paper: Grounauer, P.-A. and Métraux, B. (2018) Insomnia Fighting with Red Led Pulsations. Journal of Behavioral and Brain Science, 8, 615-621. https://doi.org/10.4236/jbbs.2018.811038

Received: June 21, 2018

Accepted: November 10, 2018

Published: November 13, 2018

Copyright $\odot 2018$ by authors and Scientific Research Publishing Inc. This work is licensed under the Creative Commons Attribution International License (CC BY 4.0).

http://creativecommons.org/licenses/by/4.0/

\begin{abstract}
This study shows how and why luminous red pulsations can distract the mind and facilitate sleep by preventing disruptive thoughts and memories. The rgb LED produces a miniature dusk-to-dawn flight device to pass from red at night to white at dawn, potentially followed by luminotherapy. Combined in a single portable device, these luminous parameters are useful in the fight against insomnia through cognitive behavioral therapy CBT.
\end{abstract}

\section{Keywords}

Insomnia, Sleepiness, SLEAPI, Luminotherapy, Chronorythm

\section{Introduction}

Insomnia represents more than a deficit in sleep time and its effects are already felt the following day. Several different methods can assist in re-establishing recovery and control [1] [2]. The easiest ways are having a short sleep, power-napping, using blue-blocking glasses for screen use or avoiding caffeine or other stimulants in the day. To avoid having to take sleeping pills, which can become addictive, we present here a new method which uses eyesight, the path to communication and boundary between the exterior and one's interior world. If the eye is a window to the world from the moment of waking, when the eyes are closed it is still a means of perceiving one's immediate surroundings. This severance of sight deprives us of the vision of shapes, colours and contrasts but does not suppress the perception of light or contact with the exterior. On the contrary, this sensory deprivation inactivates the automatic warning system, our primitive safety reflexes, and allows neuro-sensory respite, a kind of mental no-man's land.

Even if the hypothalamic centres of survival are put on standby by closing the eyes the retina does not lose contact with ambient light. To demonstrate this, we have made ERG [3] [4] recordings and proven that $618 \mathrm{~nm}-0.01 \mathrm{~cd} / \mathrm{m}^{2}$ red flashes are sufficient to stimulate closed eyes. By using slow red pulsations rather 
than flashes, the result is similar and aims to provoke continual, voluntary visual attention. This effort to concentrate on a neutral visual medium prevents the mind from wandering from one thought to the next. Note that this mental composure is not due to luminous photons but uniquely to the determination and motivation of the individual.

To fall asleep quickly, it is important to know that quality sleep starts with quality waking. This implies, according to the latest research [5] [6] waking at a fixed time along with a simulated dawn. In our study, the light spectrum (Figure 1) was chosen in order to avoid the macular phototoxicity of the blue tones between 400 and $450 \mathrm{~nm}$ whilst allowing $480 \mathrm{~nm}$ to stimulate the melanopsin which daily resets the time on our primary cerebral clock. If an outpatient luminotherapy is subsequently necessary, it can be given at an intensity of around 250 lux measured at $2 \mathrm{~cm}$ from source [7] [8] [9].

The eye, together with vision through closed eyelids, is not the only means of preventing insomnia. Hearing music, natural or man-made sounds, or the perception of certain areas of the body, can produce the same soothing effect. It is up to the individual to find the method that suits him/her. However, by choosing a light source, a unique, powerful method is available. This informational flow is comparable to an "Amazon" of inputs which penetrate and spread inside the neuronal network and flood the brain with countless data bytes that are sorted and classified then submitted to the integrative processes of signals connected to the other perceptive channels. The original benefit of this neuronal networking of ocular origin is to be able to stay upright and to walk with hands free for gripping and hunting; thus to constitute the framework for all conscious or unconscious memories. The most emotionally significant memories resurface during insomnia. The aim of our visual CBT is to prevent the mind from being

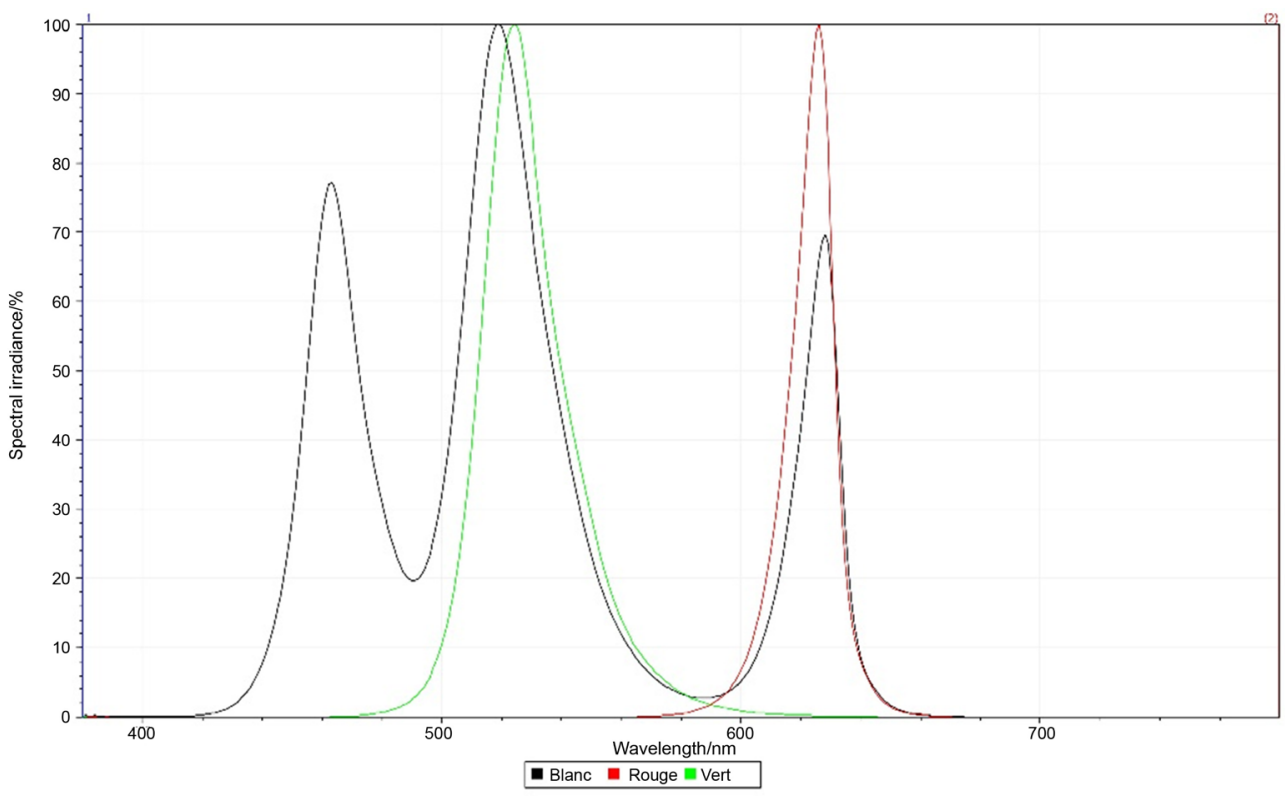

Figure 1. SLEAPI spectroscopy. Red intensity 2.2 lux - 0.8 lux//white 424 - 258 lux@2 cm from the source. Blue $463 \mathrm{~nm}$, green $519 \mathrm{~nm}$, red $628 \mathrm{~nm}$. CSTB SLEAPI expertise 2017. 
invaded by unpleasant memories. If our brain is to be capable of fulfilling our daily tasks, it requires a minimum quantity and quality of sleep uninterrupted by insomnia.

This publication aims to show how and why day-night transition is facilitated by sinusoidal red pulsations observed first with eyes open, then with eyes closed. It also serves as a reminder that the colour blue included in the white of dawn facilitates night-day transition, and encourages complementary luminotherapy, if needed. These two important moments which are waking and sleep are the pillars of chronotherapy which is indispensable to finding one's own personal genetic biological rhythm [10] [11].

This pilot study has concerned more than 20 patients following WMA Declaration of Helsinki-Ethical by the main author PAG who is ethical certified by Lausanne University.

\section{Material}

The rgb LED is placed in a small box on the forehead (Figure 2) and is preferably worn all night in a right or left lateral position but not on the abdomen or lying on the back which encourages hypopnea. Shaped like a turtle, it symbolises successful, genetically programmed sleep. A rechargeable $5 \mathrm{~V}$ battery powers the rgb LED which emits red sinusoidal pulsations lasting 7 seconds, varying from 2.2 to 0.8 lux. They are followed by an absence of light assessed and perceived as nil, a void. The rgb light spectrum shows the different wavelengths used, on which red is at $628 \mathrm{~nm}$.

\section{Method}

The task consists of observing one's surroundings in red with the eyes open, then in pink with the eyes closed. The alternating red/black periods can be timed between 10 and 50 minutes, then it switches off automatically. The program can be restarted at any time in case of untimely nocturnal waking. Assessed by the Scientific and Technical Centre for Building in Grenoble CSTB the light source has been classified as risk-free for children under the age of 2 and cataract operated patients and does not emit electromagnetic waves. A USB stick connects it to a PC (subsequently available for MAC and smartphones). This offers the possibility of integrating a clock, choosing an alarm and its tonality and also installing a simulated dawn (Figure 3) 10 minutes before the alarm rings. The device keeps in its memory all periods of day and night use for consultation by the user or the therapist. This objective assessment permits the initiation and management of a personalised chronotherapy will be discuss elsewhere.

\section{Results}

This pilot study has a prospective nature and will be the subject of a randomised, controlled research. Following sampling of insomnias of different age groups, it is suitable for adults and children. Small $(45 \times 40 \times 15 \mathrm{~mm})$ and light $(19 \mathrm{~g})$, 


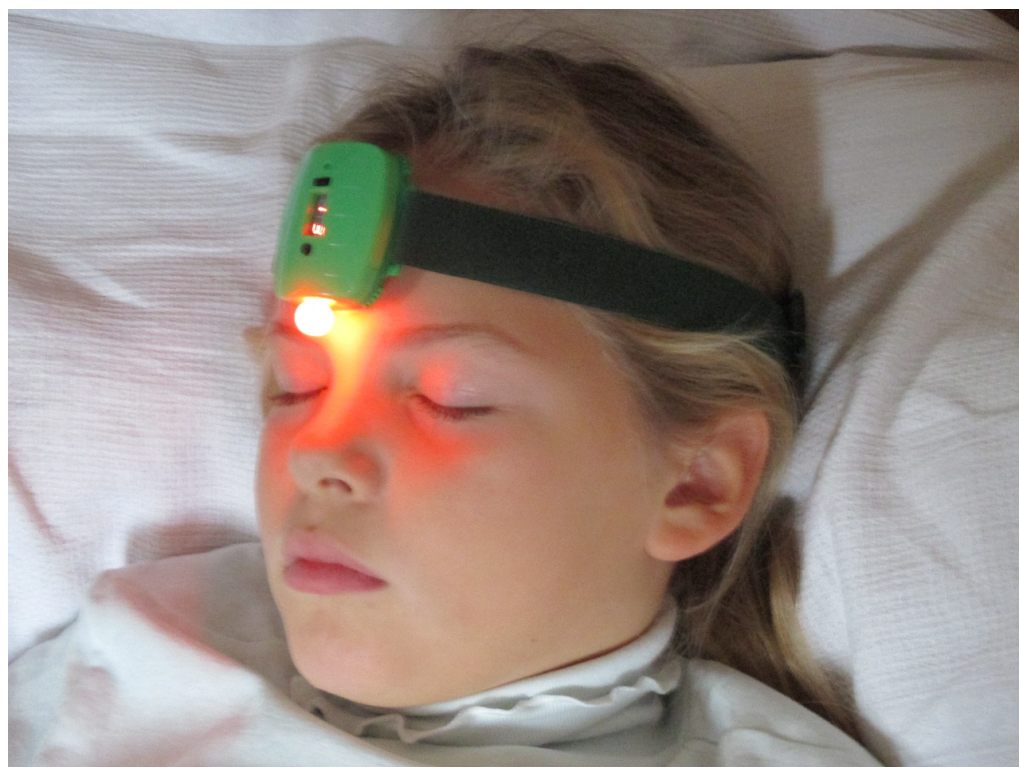

Figure 2. SLEAPI forehead best position.

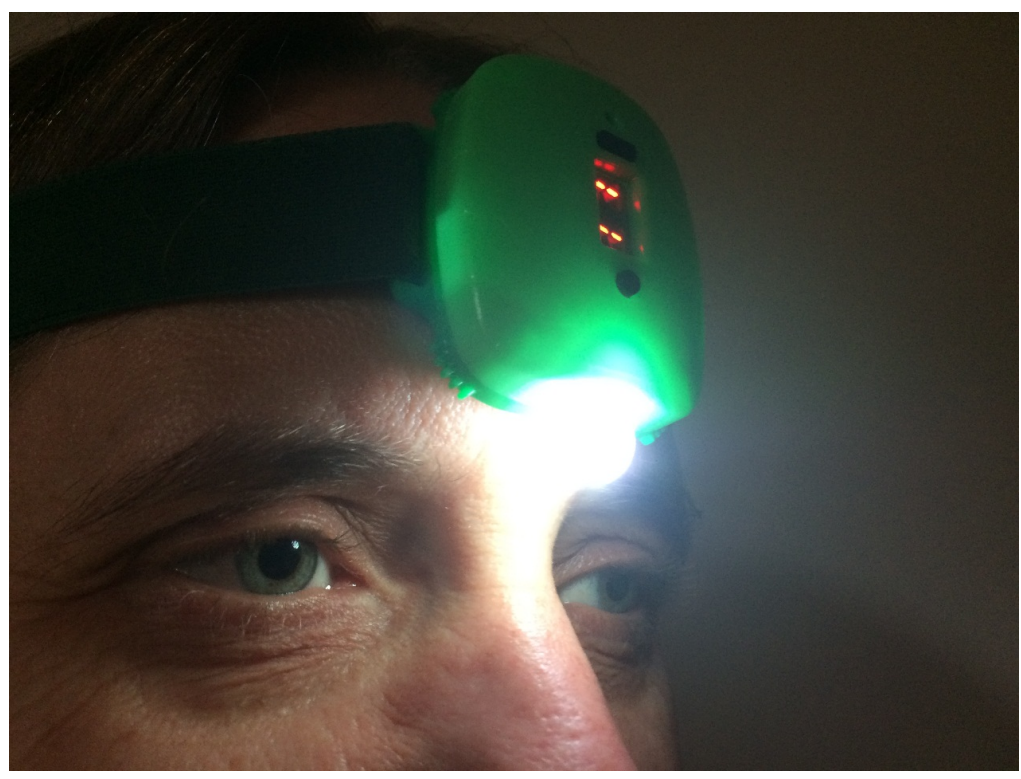

Figure 3. White light for luminotherapy.

SLEAPI sleeping light emission awaking provider instrument [12] [13] [14] [15] can stay on the forehead throughout the night or be placed beside the sleeper without disturbing the partner.

\section{Discussion}

The means of fighting insomnia are numerous: counselling in behaviour, hygiene, alimentation, nutrition and phytotherapy. In books on the subject, the authors warn of the dangers of abuse of over-prescribed benzodiazepines and their derivatives. They indicate other natural means, possibly associated with synthetic slow-release or spray melatonin which is sold as a food supplement in 
some countries. Associated with CBT this synthetic molecule increases the effect of our psycho-physical method whose principal depends entirely on one's determination to scrupulously observe the red pulsations. Their appearance/disappearance is followed by a black veil which invades the field of vision. At this precise moment the veil induces a sentiment of calm and relief. To fully appreciate its advantages, the ritual must be repeated every night at the same time and a fixed waking time must be chosen.

This study aims to show that it is possible to forego medication as long as CBT is practised daily. It is based notably on the fact that long wavelengths are retained less by the palpebral filter, particularly red at $630 \mathrm{~nm}$. A very weak degree of red of 2.2 lux is easily perceived without upsetting the release of melatonin. By sinusoidally modulating it, this variation of intensity over time arouses curiosity, attention and interest. Using cerebral infrared fNIRS spectroscopy of the prefrontal neocortex we have shown that this visual task specifically modifies the anterior cerebral zone while sparing the occipital visual cortex. This mental effort significantly modifies the blood flow from the prefrontal brain after 120 seconds of visual work, apparently prioritising the right side.

We conclude that the essence of the work takes place in the prefrontal cortex zone, conducive to attention and determination and we speculate that this increase would penalise that of the amygdala [16]. To provide proof we would need to perform fMNI associated with fNIRS concurrently. In addition to the vascular variations in the brain, somnogen visual training SVT would modify the neuronal excitation/inhibition balance of the amygdala, seat of distress and emotional fear. These two vascular and neuronal parameters probably explain why and how this luminous device acts on the mind by preventing the memory of unpleasant feelings. This means of perceiving black evokes neutral or a void and the patient becomes indifferent and liberated from obsessive preoccupations. This is precisely what we desire when we go to bed: to manage to fall asleep as quickly as possible by erasing anything that could disrupt sleep in the course of the night.

If these hypotheses are proven relevant and verified, SVT can be complemented by other means. We will consider three: breathing [17] the muscle tone of the lower limbs [18] and the perineum [19] Firstly, breathing deserves a role and a place of choice. We have observed that the simple practice of exhaling slowly and fully a few times helps make CBT more effective. Voluntarily reducing the tonus of the legs according to Schultz's autogenic training method is also useful. Finally, conscious relaxation of the Muladhara perineum centre helps to consolidate the method. All of these additional exercises require neuroplasticity and confirm the statement "train your mind to change your brain" as long as they are practised daily [20].

\section{Conclusion}

This study allows us to understand how and why red pulsations, possibly associ- 
ated with breathing and a decrease in the muscle tone of the legs and the perineum, can become a useful, non-drug means of fighting insomnia. It proposes a luminous device diffusing a double light spectrum; red to insure day-night transition and white for passing from night to waking. In effect, to treat insomnia alone without taking into account the chronotype and waking time is like wandering aimlessly, sleeping useful starts with waking well.

\section{Acknowledgements}

Patrick Lemoine, Thierry Faivre, Gérard Pons the team Jacques and Niki Fournier - S Pracchinetti - D Vigo - M Bonnefoy - VG - Louise G - Rose G and our tested patients.

\section{Conflicts of Interest}

The authors declare no conflicts of interest regarding the publication of this paper.

\section{References}

[1] Pavlova, B., Perroud, N.A., Cordera, P., Uher, R., Alda, M., Dayer, A. and Aubry, J.-M. (2018) Anxiety Disorders and Childhood Maltreatment as Predictors of Outcome in Bipolar Disorder. Journal of Affective Disorders, 225, 337-341. https://doi.org/10.1016/j.jad.2017.08.048

[2] Pichon, S.J.A., Miendlarzewska, E., Eryilmaz, H. and Vuilleumier, P. (2015) Cumulative Activation during Positive and Negative Events and State Anxiety Predicts Subsequent Inertia of Amygdala. Social Cognitive and Affective Neuroscience, 10, 180-190. https://doi.org/10.1093/scan/nsu044

[3] Grounauer, P.A. and Métraux, B. (2014) The Somnogen Visual Training a New CBT to Fight Insomnia through closed eyes and fNIRS Neuroimaging. Journal of Behavioral and Brain Science, 4, 477-481. https://doi.org/10.4236/jbbs.2014.410047

[4] Grounauer, P.A. and Métraux, B. (2015) Prefrontal fNIRS Neuroimaging during a Sleep Induction Task Using Perception of a Red Light through Closed Eyes to Fight Insomnia: A Pilot Study. In: Toi, V. and Lien Phuong, T., Eds., 5th International Conference on Biomedical Engineering in Vietnam, IFMBE Proceedings, Vol. 46. Springer, Cham.

[5] Lemoine, P. (2017) Doctor Idont Sleep (Docteur je ne dors pas). Edition In Press, $126 \mathrm{p}$.

[6] Lemoine, P. (2018) Clock Your Bell at Time (Remettez vos pendules à l'heure). Edition In Press, 130 p.

[7] http://www.cstb.fr/cstb/etablissements/grenoble/

[8] Behar-Cohen, F., et al. (2011) Light Emitting Diodes (LED) for Domestic Lighting: Any Risk for the Eye. Elsevier 30, 232-257.

[9] http://www.pointsdevue.com/sites/default/files/lumiere-bleue-quels-sont-ses-risque s-pour-les-yeux-final.pdf

[10] Chronotherapy, M. and Terman, I. (2012) MacMahan. Penguin Group, 312 p.

[11] Wirz-Justice, A., Benedetti, F. and Terman, M. (2013) Chronotherapeutics for Affective Disorders. Karger, 124 p. 
[12] http://www.sleapi.com

[13] SFRMS Poster Marseille 2017.

[14] http://www.sfrms-sommeil.org

[15] http://sltbr.org

[16] Perlmutter, D. and Villoldo, A. (2013) Power up Your Brain (Neuroscience et chamanisme). Editions Véga.

[17] Christen, E. (1996) At Body Center the Breath (Au centre du corps, le souffle). Edition LEP, Le Mont-sur-Lausanne.

[18] https://en.wikipedia.org/wiki/Autogenic_training

[19] https://www.philosophie-spiritualite.com/cours/centres_psy.htm

[20] https://www.nobelprize.org/prizes/medicine/2017/summary 